\title{
Magnesium Sulfate Has Potential Scavenging Effects on Cyclophosphamide-Induced Ovarian Damage in A Rat Model
}

(1) Illkin YERALa,

(D) Cemile DAYANGAN SAYAN ${ }^{\mathrm{a}}$

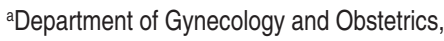
Kırıkale University Faculty of Medicine, Kırıkkale, TURKEY

Received: 06.02.2019

Received in revised form: 26.02 .2019

Accepted: 28.02 .2019

Available online: 19.03 .2019

\section{Correspondence:}

IIlkin YERAL

Kırıkkale University Faculty of Medicine, Department of Gynecology and Obstetrics, KIrıkkale, TURKEY

ilkinyeraldr@hotmail.com
Copyright @ 2019 by Türkiye Klinikleri

\begin{abstract}
Objective: This study proposed to investigate whether magnesium sulfate $\left(\mathrm{MgSO}_{4}\right)$ could reduce the ovarian damage induced by cyclophosphamide (Сус). Material and Methods: Thirty female rats were used for this study: Control group $(n=10)$ - Only laparotomy; Cyc group $\mathrm{n}=10)-75 \mathrm{mg} / \mathrm{kg}$ Cyc intraperitoneally; and $\mathrm{Cyc}+\mathrm{MgSO}_{4}$ group $(\mathrm{n}=10)-75 \mathrm{mg} / \mathrm{kg}$ Cyc on day 0 and $200 \mathrm{mg} / \mathrm{kg} \mathrm{MgSO}_{4}$ on days 1-7 (both intraperitoneally). The extent of histopathological damage and the number of ovarian follicles were determined. The levels of anti-Mullerian hormone (AMH) were measured in blood samples. Results: Statistically significant differences in the AMH values were observed in the control group versus $\mathrm{Cyc}$ group and $\mathrm{Cyc}$ group versus $\mathrm{Cyc}+\mathrm{MgSO}_{4}$ group $(\mathrm{p}<0.05)$. The levels of AMH were the least in the Cyc group. The total tissue damage in the Cyc group was significantly higher than that in the control, as well as in the $\mathrm{Cyc}+\mathrm{MgSO}_{4}$ group $(\mathrm{p}<0.05)$. The follicle counts were the least in the Cyc group. Conclusion: Cyc caused ovarian damage and reduced the ovarian reserves. The ovarian reserves in the $\mathrm{MgSO}_{4}$-treated group were better than those in the other groups, and there was least ovarian damage in the $\mathrm{MgSO}_{4}$-treated group.
\end{abstract}

Keywords: Cyclophosphamide; anti-Mullerian hormone; magnesium sulfate

hemotherapeutic agents, which are presently widely used in the treatment of cancer, are highly effective but have a high incidence of side effects. ${ }^{1}$ Various chemotherapeutic agents may be selected based on the type of cancer. Among chemotherapeutics, cyclophosphamide (Сyc) is one of the most effective alkylating agents but is also one of the most toxic to the ovaries. ${ }^{1}$ Cyc affects the ability of ovarian primordial follicular cells to regenerate, and damage to these cells can cause ovarian dysfunction and premature ovarian failure. ${ }^{2}$ Thus, the use of Cyc in reproductive women puts them at high risk of premature menopause and infertility. ${ }^{3}$

Anti-Mullerian hormone (AMH) is a dimeric glycoprotein produced from granulosa cells in preantral (primary) follicles, particularly antral follicles. Very large antral follicles (larger than $5 \mathrm{~mm}$ in size) lose their ability to produce $\mathrm{AMH}$, thus inhibiting adjacent primordial follicles by exerting a negative paracrine effect. ${ }^{4}$ Serum levels of $\mathrm{AMH}$ can provide information about ovarian reserves. ${ }^{5,6} \mathrm{AMH}$ is a better marker of ovarian reserves than estradiol, inhibin, or follicle-stimulating hormone. ${ }^{7}$ 
Previous research has demonstrated the strong anti-inflammatory, antioxidant, and anti-apoptotic effects of magnesium sulfate $\left(\mathrm{MgSO}_{4}\right)$, which inhibits the endotoxin-dependent inflammatory molecules. ${ }^{8}$ Previous studies have also demonstrated the protective effects of $\mathrm{MgSO}_{4}$ in lung, kidney, and brain. ${ }^{8-10}$ However, none of these studies investigated the protective effect of $\mathrm{MgSO}_{4}$ on the ovaries. The aim of this study was to evaluate the potential ability of $\mathrm{MgSO}_{4}$ to reduce ovarian damage induced by Cyc.

\section{MATERIAL AND METHODS}

The study was approved by the Kırıkkale University's Animal Experiments Local Ethics Committee on 09.11.2017 (meeting number 17/7 and decision number 17/39) and was performed according to the criteria of the National Health and Medical Research Council. The study was carried out in accordance with the principles of the Declaration of Helsinki.

\section{ANIMALS}

Thirty female Wistar-Albino rats aged 10-12 weeks (weight 200-250 g) were used. The animals were fed standard rat chow and had unrestricted access to tap water. They were housed in cages at room temperature $\left(22-25^{\circ} \mathrm{C}\right)$ under a 12 -h light/12-h dark cycle.

\section{STUDY GROUPS}

Three groups were established, with 10 rats in each group: 1) Control group: Only a laparotomy was performed on day 7; 2) Cyc group: A single dose of $75 \mathrm{mg} / \mathrm{kg}$ of cyclophosphamide (Eczacibasi; Baxter Chemical Co., Istanbul, Turkey) was administered intraperitoneally on day 0; and 3) $\mathrm{Cyc}+\mathrm{MgSO}_{4}$ group: A single dose of $75 \mathrm{mg} / \mathrm{kg}$ of Cyc was administered on day 0 , and $200 \mathrm{mg} / \mathrm{kg}$ of $\mathrm{MgSO}_{4}$ (both intraperitoneal) was administered on days 17.

\section{ANESTHESIA}

Anesthesia was induced by the intramuscular administration of $5 \mathrm{mg} / \mathrm{kg}$ of $2 \%$ xylazine (Rompun ${ }^{\circledR}$ vet, Bayer AG, Leverkusen, Germany) and $50 \mathrm{mg} / \mathrm{kg}$ of $10 \%$ ketamine $\left(\operatorname{Ketaminol}^{\circledR}\right.$ vet, Farmaceutici Gellini SpA, Aprilia, Italy).

\section{SURGICAL METHODS}

At the end of one week, the animals from all the groups were surface-sterilized in the supine position and a $2-\mathrm{cm}$ midline vertical incision was made. Bilateral oophorectomy was performed and intracardiac blood samples $(5 \mathrm{~mL})$ were collected. All the operations were performed by the same researcher.

\section{MEASUREMENT OF SERUM AMH LEVELS}

The blood samples were centrifuged at $1000 \mathrm{rpm}$ for $20 \mathrm{~min}$ and the obtained serum samples were stored at $-80^{\circ} \mathrm{C}$ until further use. The serum was diluted 1:30 with distilled water and the serum $\mathrm{AMH}$ values were measured using an enzymelinked immunosorbent assay kit (Cusabio, MD, USA).

\section{HISTOPATHOLOGICAL ANALYSIS}

Tissues from the right ovary were fixed in $10 \%$ formalin and then embedded in paraffin. Serial sections of $5 \mu \mathrm{m}$ thickness were cut and stained with hematoxylin-eosin. All the specimens were examined by light microscopy (Olympus BX50F4; Olympus, Tokyo, Japan), wherein at least five fields per specimen were scanned at a minimum magnification of 10 -fold. A single pathologist blinded to the specimen group performed the examination and scoring of the samples (Figure 1a).

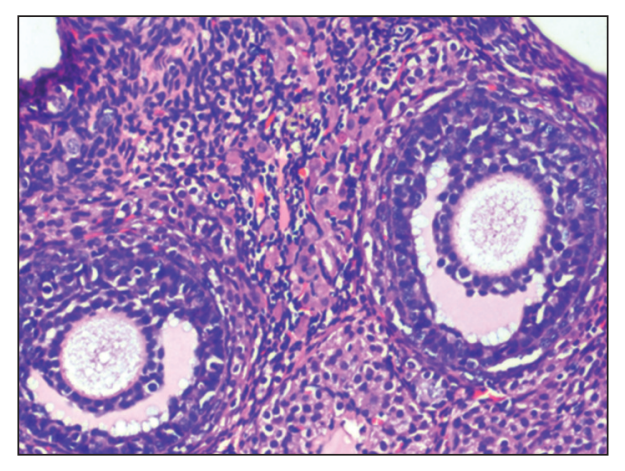

FIGURE 1a: Primordial follicle in the sham group (H-E; X200). 


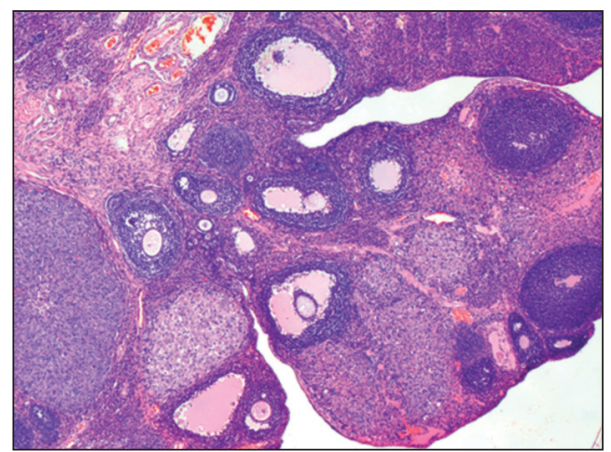

FIGURE 1b: Follicular degeneration in the Cyc group (H-E; X40).

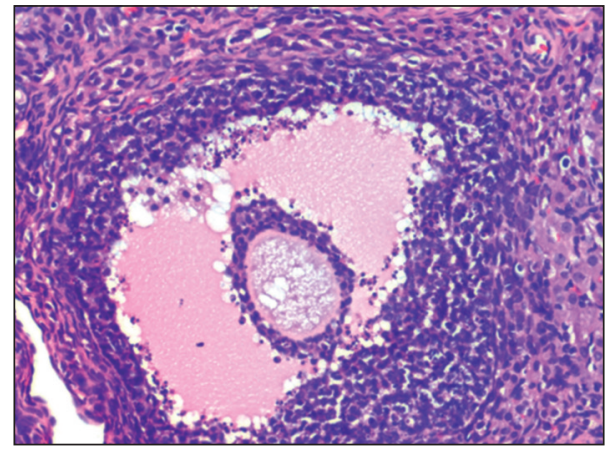

FIGURE 1c: The degenerated follicle in the Cyc group (H-E; X200),

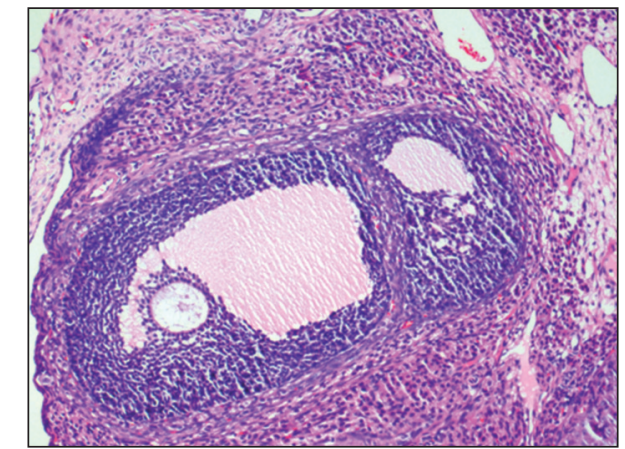

FIGURE 1d: The intact follicle in the $\mathrm{Cyc}+\mathrm{MgSO}_{4}$ group ( $\left.\mathrm{H}-\mathrm{E} ; \mathrm{X} 100\right)$.

The follicles in the ovaries were divided into four groups based on their size: primordial follicles $(<20 \mu \mathrm{m})$, preantral follicles $(20-220 \mu \mathrm{m})$, small antral follicles $(221-310 \mu \mathrm{m})$, and large antral follicles (311-370 $\mu \mathrm{m})$. For follicle counts, both the follicle size and total number were recorded.

The level of ovarian damage was evaluated using a histopathological damage-scoring system (Figure 1b, Figure 1c, Figure 1d). According to this system, follicular cell degeneration, vascular congestion, hemorrhage, and inflammation levels were scored as 0 (none), 1 (mild), 2 (moderate), and 3 (severe) based on damage of less than $25 \%$, between 25 and $50 \%$, between 50 and $75 \%$, and over $75 \%$, respectively. The scores were added up to determine the total tissue damage.

\section{STATISTICAL ANALYSIS}

All the results were reported as the average standard deviation of mean values. The statistical analyses were performed using the software SPSS, version 16.0 (Chicago, IL). Due to the limited number of rats in each group, nonparametric methods were used for the statistical analysis. Differences among the three groups were evaluated with Kruskal-Wallis's variance analysis. Pair-wise comparisons were done with Mann-Whitney's U-test. A value of $\mathrm{p}<0.05$ was considered to be statistically significant.

\section{RESULTS}

The serum AMH values and parameters of ovarian damage such as hemorrhage, congestion, inflammation, follicle degeneration, total tissue damage, and follicle number in the ovarian tissues were compared between different groups. The examined parameters in the control group and the $\mathrm{Cyc}+\mathrm{MgSO}_{4}$ group were found to be statistically similar $(\mathrm{p}>0.05)$.

The serum AMH values of the control and Cyc groups, and those of the $\mathrm{Cyc}$ and $\mathrm{Cyc}+\mathrm{MgSO}_{4}$ groups were significantly different $(\mathrm{p}<0.05)$. The Cyc group showed the least serum AMH values, while the control group showed the highest (Table 1).

In terms of tissue damage, a statistically significant difference in the follicular degeneration and total tissue damage was observed between the control and Cyc groups, and between the Cyc and $\mathrm{Cyc}+\mathrm{MgSO}_{4}$ groups $(\mathrm{p}<0.05)$. The Cyc group showed the highest follicular degeneration and total tissue damage (Table 2).

The number of primordial follicles, preantral follicles, small antral follicles, large antral folli- 


\begin{tabular}{|c|c|}
\hline \multicolumn{2}{|c|}{$\begin{array}{l}\text { TABLE 1: Biochemical results of the groups (mean } \pm S D \text { ) and } \\
\text { p values of the multiple comparison test results between } \\
\text { the groups. }\end{array}$} \\
\hline Groups & AMH (pg/ml) \\
\hline Sham $(n=10)$ & $13.66 \pm 8.49$ \\
\hline Cyc $(n=10)$ & $6.16 \pm 0.76$ \\
\hline $\mathrm{Cyc}+\mathrm{MgSO}_{4}(\mathrm{n}=10)$ & $9.22 \pm 2.70$ \\
\hline \multicolumn{2}{|l|}{$p$-value $e^{*}$} \\
\hline Sham vs Cyc & $p<0.05$ \\
\hline Sham vs $\mathrm{Cyc}+\mathrm{MgSO}_{4}$ & $p=0.280$ \\
\hline Cyc vs $\mathrm{Cyc}+\mathrm{MgSO}_{4}$ & $p<0.05$ \\
\hline
\end{tabular}

${ }^{*} p<0.05$ value was considered as statistically significant. SD: Standard deviation, AMH: Anti-Mullerian hormone, Cyc: Cyclophosphamide $\mathrm{MgSO}_{4}$ : Magnesium sulfate.

cles, and the total number of follicles was statistically different between the control and the Cyc group, and between the Сyc and the
$\mathrm{Cyc}+\mathrm{MgSO}_{4}$ group $(\mathrm{p}<0.05)$. The Cyc group showed the least number of primordial follicles, preantral follicles, small antral follicles, and large antral follicles, as well as the total number of follicles (Table 3).

\section{DISCUSSION}

To the best of our knowledge, the effect of $\mathrm{MgSO}_{4}$ against Cyc-induced ovarian damage in rat models has not been investigated yet. The results of our study indicated that Cyc caused ovarian damage and reduced the ovarian reserve. The ovarian reserves in the $\mathrm{MgSO}_{4}$-treated group were better than those in the other groups and there was least ovarian damage in the $\mathrm{MgSO}_{4}$ treated group.

Cyc shows cytotoxic effects, especially against rapidly dividing cells. ${ }^{1}$ Hence, an important side-

TABLE 2: Histopathological results of the groups (mean $\pm S D$ ) and $p$ values of the multiple comparison test results between the groups.

\begin{tabular}{|c|c|c|c|c|c|}
\hline Group & Hemorrhage & Congestion & Inflammation & Follicular degeneration & Total damage \\
\hline Sham $(n=10)$ & $0.00 \pm 0.00$ & $1.00 \pm 0.00$ & $0.50 \pm 0.52$ & $0.30 \pm 0.48$ & $1.80 \pm 0.78$ \\
\hline Cyc $(n=10)$ & $0.00 \pm 0.00$ & $1.00 \pm 0.00$ & $0.9 \pm 0.31$ & $1.00 \pm 0.00$ & $2.90 \pm 0.31$ \\
\hline $\mathrm{Cyc}+\mathrm{MgSO}_{4}(\mathrm{n}=10)$ & $0.00 \pm 0.00$ & $1.00 \pm 0.00$ & $0.4 \pm 0.51$ & $0.40 \pm 0.51$ & $1.60 \pm 0.84$ \\
\hline \multicolumn{6}{|l|}{$p$-value } \\
\hline Sham vs Cyc & $p=1.00$ & $p=1.00$ & $\mathrm{p}=0.143$ & $p<0.05$ & $p<0.05$ \\
\hline Sham vs $\mathrm{Cyc}+\mathrm{MgSO}_{4}$ & $p=1.00$ & $p=1.00$ & $p=0.739$ & p: 0.739 & $\mathrm{p}=0.579$ \\
\hline Cyc vs $\mathrm{Cyc}+\mathrm{MgSO}_{4}$ & $p=1.00$ & $p=1.00$ & $p=0.63$ & $p<0.05$ & $p<0.05$ \\
\hline
\end{tabular}

${ }^{*} p<0.05$ value was considered as statistically significant.

SD: Standard deviation, Cyc: Cyclophosphamide, $\mathrm{MgSO}_{4}$ : Magnesium sulfate.

TABLE 3: Follicle counts of the groups (mean $\pm S D$ ) and $p$ values of the multiple comparison test results between the groups.

\begin{tabular}{|c|c|c|c|c|c|}
\hline Group & Hemorrhage & Congestion & Inflammation & Follicular degeneration & Total damage \\
\hline Group & Primordial & Preantral & Small antral & Large antral & Number of follicule \\
\hline Sham $(n=10)$ & $3.20 \pm 1.81$ & $1.70 \pm 0.82$ & $2.50 \pm 1.64$ & $2.00 \pm 1.33$ & $9.40 \pm 3.62$ \\
\hline Cyc $(n=10)$ & $1.40 \pm 1.17$ & $0.70 \pm 0.82$ & $0.90 \pm 1.28$ & $0.60 \pm 0.69$ & $3.60 \pm 2.63$ \\
\hline Cyc+MgSO $4(n=10)$ & $4.50 \pm 2.32$ & $2.70 \pm 2.31$ & $2.90 \pm 1.79$ & $2.90 \pm 2.23$ & $13.00 \pm 4.76$ \\
\hline \multicolumn{6}{|l|}{$p$-value* } \\
\hline Sham vs Cyc & $p<0.05$ & $p<0.05$ & $p<0.05$ & $p<0.05$ & $p<0.05$ \\
\hline Sham vs $\mathrm{Cyc}+\mathrm{MgSO}_{4}$ & $p=0.218$ & $p=0.436$ & $p=0.684$ & $p=0.436$ & $p=0.052$ \\
\hline Cyc vs $\mathrm{Cyc}+\mathrm{MgSO}_{4}$ & $p<0.05$ & $p<0.05$ & $p<0.05$ & $p<0.05$ & $p<0.05$ \\
\hline
\end{tabular}

${ }^{*} \mathrm{p}<0.05$ value was considered as statistically significant.

SD: Standard deviation, Cyc: Cyclophosphamide, $\mathrm{MgSO}_{4}$ : Magnesium sulfate. 
effect of Cyc is ovarian insufficiency, which can occur as a result of ovarian follicular damage. ${ }^{1}$ Several studies have examined ovarian toxicity induced by Cyc and other chemotherapeutic agents in various animal models. ${ }^{11-13}$ As the toxicity by Cyc surpasses that of most of the other chemotherapeutic agents, the present study focused on the effects of Cyc. Based on the results of the serum and tissue analyses, the ovarian reserve in the Cyc group was the least.

In a previous study on Cyc-induced ovarian toxicity in rats, the number of follicles increased in a group treated with an antagonist of the gonadotropin-releasing hormone $(\mathrm{GnRH}) .{ }^{11} \mathrm{In}$ another study using rat models, a specific inhibitor of tyrosine-specific protein kinases called genistein provided a protective effect against ovarian toxicity induced by Cyc. ${ }^{12}$ In other studies, antioxidants such as ascorbic acid, alpha-tocopherol, and selenium reduced Cyc-induced toxicity in rat ovaries. ${ }^{13}$ Furthermore, few other studies have reported that dienogest and the blue-green alga spirulina, which has known antioxidant and antiapoptotic properties, provided protection against Cyc-induced toxicity in rat ovaries. ${ }^{14,15}$

A previous study demonstrated that treatment with $\mathrm{MgSO}_{4}$ prevented the damage of oligodendrocytes after the induction of cerebral ischemiareperfusion in rats. ${ }^{10}$ In this study, the treatment with $\mathrm{MgSO}_{4}$ appeared to reduce the ovarian damage induced by treatment with Cyc.

The glycoprotein $\mathrm{AMH}$ is a member of the transforming growth factor-B (TGF-B) family, and its structure is similar to that of inhibin and activin. ${ }^{16}$ Previous research has demonstrated that serum AMH is a sensitive marker of decreased ovarian reserve and apoptosis caused by cisplatin. ${ }^{17}$ Human studies support the role of serum $\mathrm{AMH}$ levels as a reliable marker of ovarian reserves. ${ }^{18}$ Thus, we used serum AMH levels as an indicator of ovarian reserves in the present study and validated our findings using histopathological scores or follicle counts. The findings from the serum $\mathrm{AMH}$ levels and tissue histopathological scores were consistent. A study comparing serum $\mathrm{AMH}$ values before and after exposure to cisplatin-induced ovarian toxicity reported decreased ovarian reserves following drug exposure. ${ }^{19}$ In the present study, wherein serum $\mathrm{AMH}$ levels were compared between groups following Cyc-induced toxicity, the serum AMH values were lower in the rats exposed to Cyc, as compared to those in the other groups.

As noted earlier, chemotherapeutic agents are effective against rapidly dividing cells. Although this is beneficial while combating malignancy, it has negative consequences for rapidly dividing healthy cells, which are also killed by chemotherapeutic drugs. By reducing the number of follicles, these drugs result in a decrease in the ovarian reserve. As a result, ovarian failure and infertility may occur. The effects of chemotherapeutics on the ovaries are dose-dependent, and they mainly affect the number of primordial follicles. Chemotherapeutics exert primary (direct follicle damage) and secondary (decrease in the number of antral follicles) effects on the ovarian reserve. Thus, an actual decrease in the ovarian reserve is not apparent until a later period during which secondary effects occur. In a previous study, the numbers of primordial and preantral follicles were significantly lower in a cisplatin-treated group as compared with controls, whereas there was no significant difference in the number of antral follicles between the groups. ${ }^{19}$ In the present study, although the decrease in follicle number was most apparent in the primordial follicles, there was a statistically significant decrease in all the follicle types in the Cycadministered group compared to that in the control group. This difference may be attributed to the greater ovarian toxicity induced by Cyc compared to cisplatin. Atli et al. evaluated ovarian changes induced by cisplatin and resveratrol in rats that received a low dose of resveratrol and saline for 21 days. ${ }^{20}$ On day 15 , the animals in both groups received a single dose of cisplatin. In the resveratrol group, the numbers of primordial and preantral (primary) follicles were significantly higher than those in the saline group. In the resveratrol group, the numbers of primordial and preantral (primary) 
follicles were significantly higher than those in the saline group, indicating that resveratrol reversed the toxic effects of cisplatin. Thus, resveratrol could also be a potential agent to reverse the cytotoxic effects of chemotherapeutics. ${ }^{20}$

\section{CONCLUSION}

In conclusion, our findings indicate that $\mathrm{MgSO}_{4}$ appears to have a protective effect and may even be able to reverse the damage caused by Cyc to the ovaries. However, the results need to be supported further by more extensive studies on animal models as well as humans.

\section{Acknowledgments}

The authors thank Tuba Devrim, Department of Pathology, Kirikkale University Faculty of Medicine, Kirikkale, Turkey for assistance with the histopathology and Gökhan Karaca, Department of General Surgery, Kirikkale University Faculty of Medicine, Kirikkale, Turkey for assistance with the laboratory work.

\section{Source of Finance}

This research was funded by Kirıkkale University Scientific Research Commission (Project number: 2018/002). The authors are grateful to the staff members of Kirıkkale University for their valuable support.

\section{Conflict of Interest}

No conflicts of interest between the authors and / or family members of the scientific and medical committee members or members of the potential conflicts of interest, counseling, expertise, working conditions, share holding and similar situations in any firm.

\section{Authorship Contributions}

Idea/Concept: İlkin Yeral, Design: IIlkin Yeral, Control/Supervision: İlkin Yeral, Data Collection and/or Processing: İlkin Yeral, Cemile Dayangan Sayan, Analysis and/or Interpretation: İlkin Yeral, Cemile Dayangan Sayan, Literature Review: IIlkin Yeral, Writing the Article: IIlkin Yeral, Critical Review: IIlkin Yeral, References and Fundings: İlkin Yeral, Materials: IIlkin Yeral.

\section{REFERENCES}

1. Tomao F, Spinelli GP, Panici PB, Frati L, Tomao S. Ovarian function, reproduction and strategies for fertility preservation after breast cancer. Crit Rev Oncol Hematol. 2010;76(1):112. [Crossref] [PubMed]

2. Chapman RM. Effect of cytotoxic therapy on sexuality and gonadal function. Semin Oncol. 1982;9(1):84-94. [PubMed]

3. Oktem O, Oktay K. Quantitative assessment of the impact of chemotherapy on ovarian follicle reserve and stromal function. Cancer. 2007;110(10):2222-9. [Crossref] [PubMed]

4. Carlsson IB, Scott JE, Visser JA, Ritvos O, Themmen AP, Hovatta O. Anti-Mullerian hormone inhibits initiation of growth of human primordial ovarian follicles in vitro. Hum Reprod. 2006;21(9):2223-7. [Crossref] [PubMed]

5. Pigny $\mathrm{P}$, Merlen $\mathrm{E}$, Robert $\mathrm{Y}$, Cortet-Rudelli C, Decanter C, Jonard S, et al. Elevated serum level of anti-mullerian hormone in patients with polycystic ovary syndrome: relationship to the ovarian follicle excess and to the follicular arrest. J Clin Endocrinol Metab. 2003;88(12):5957-62. [Crossref] [PubMed]
6. Coskun B, Dilbaz B, Karadag B, Coskun B, Tohma YA, Dur R, et al. The role of anti-Mullerian hormone in predicting the response to clomiphene citrate in unexplained infertility. Taiwan J Obstet Gynecol. 2018;57(5):713-7. [Crossref] [PubMed]

7. Piltonen $\mathrm{T}$, Morin-Papunen $\mathrm{L}$, Koivunen $\mathrm{R}$, Perheentupa A, Ruokonen A, Tapanainen JS. Serum anti-Müllerian hormone levels remain high until late reproductive age and decrease during metformin therapy in women with polycystic ovary syndrome. Hum Reprod. 2005;20(7):1820-6. [Crossref] [PubMed]

8. Kao MC, Jan WC, Tsai PS, Wang TY, Huang CJ. Magnesium sulfat emitigates lung injury induced by bilateral lower limb ischemia-reperfusion in rats. J Surg Res. 2011;171:97-106. [Crossref] [PubMed]

9. Akan M, Ozbilgin S, Boztas N, Celik A, Ozkardesler S, Ergur BU, et al. Effect of magnesium sulfate on renal ischemia-reperfusion injury in streptozotocin-induced diabetic rats. Eur Rev Med Pharmacol Sci. 2016;20(8): 1642-55. [PubMed]

10. Itoh K, Maki T, Shindo A, Egawa N, Liang AC, Itoh $\mathrm{N}$, et al. Magnesium sulfate protects oligodendrocyte lineage cells in a rat cell-culture model of hypoxic-ischemic injury. Neurosci Res. 2016;106:66-9. [Crossref] [PubMed] [PMC]

11. Lemos CN, Reis FM, Pena GN, Silveira LC, Camargos AF. Assessment of fertility protection and ovarian reserve with $\mathrm{GnRH}$ antagonist in rats undergoing chemotherapy with cyclophosphamide. Reprod Biol Endocrinol. 2010;8:51. [Crossref] [PubMed] [PMC]

12. Saleh DO, Mansour DF. Ovario-protective effects of genistein against cyclophosphamide toxicity in rats: role of anti-müllerian hormone and oestradiol. Eur J Pharmacol. 2016;789:163-71. [Crossref] [PubMed]

13. Gürgen SG, Erdoğan D, Elmas C, Kaplanoğlu GT, Ozer C. Chemoprotective effect of ascorbicacid, a-tocopherol, and selenium on cyclophosphamide-induced toxicity in the rat ovarium. Nutrition. 2013;29(5):777-84. [Crossref] [PubMed]

14. Tsuyoshi H, Orisaka M, Fukuda S, Hattori K, Tsang BK, Yoshida Y. Protective effect of dienogest on chemotherapy-induced reduced fertility in female rats. Steroids. 2015;93:1-7. [Crossref] [PubMed] 
15. Yener NA, Sinanoglu O, Ilter E, Celik A, Sezgin G, Midi A, et al. Effects of spirulina on cyclophosphamide-induced ovarian toxicity in rats: biochemical and histomorphometric evaluation of the ovary. Biochem Res Int. 2013;2013:764262. [Crossref] [PubMed] [PMC]

16. Visser JA, de Jong FH, Laven JS, Themmen AP. Anti-Müllerian hormone: a new marker for ovarian function. Reproduction. 2006;131(1): 1-9. [Crossref] [PubMed]
17. Yeh J, Kim B, Liang YJ, Peresie J. Müllerian inhibiting substance as a novel biomarker of cisplatin-induced ovarian damage. Biochem Biophys Res Commun. 2006;348(2):337-44. [Crossref] [PubMed]

18. van Rooij IA, Broekmans FJ, te Velde ER, Fauser BC, Bancsi LF, de Jong FH, et al. Serum anti-Müllerian hormone levels: a novel measure of ovarian reserve. Hum Reprod. 2002;17(12):3065-71. [Crossref] [PubMed]
19. Dayangan Sayan C, Tulmac OB, Karaca G, Ozkan ZS, Yalcin S, Devrim T, et al. Could erythropoietin reduce the ovarian damage of cisplatin in female rats? Gynecol Endocrinol. 2018;34(4):309-13. [Crossref] [PubMed]

20. Atli M, Engin-Ustun $Y$, Tokmak A, Caydere M, Hucumenoglu S, Topcuoglu C. Dose dependent effect of resveratrol in preventing cisplatininduced ovarian damage in rats: an experimental study. Reprod Biol. 2017;17(3): 274-80. [Crossref] [PubMed] 